Article

\title{
Occurrence and Distribution of Apolygus lucorum on Weed Hosts and Tea Plants in Tea Plantation Ecosystems
}

\author{
Yueyue Tian ${ }^{1}$, Hanyue Wang ${ }^{1}$, Jian Hou ${ }^{2}$, Lixia Zhang ${ }^{1}$, Zhengqun Zhang ${ }^{1, *} \mathbb{C}$ and \\ Xiaoming $\mathrm{Cai}^{3, *}$ \\ 1 College of Horticulture Science and Engineering, Shandong Agricultural University, Tai'an 271018, China; \\ yueyueer8023@163.com (Y.T.); chaxuewanghanyue@163.com (H.W.); zlx_sdau@163.com (L.Z.) \\ 2 Lanshan Tea Administration, Rizhao 276808, China; houjiantaian@163.com \\ 3 Tea Research Institute, Chinese Academy of Agricultural Science, Hangzhou 310008, China \\ * Correspondence: zqzhang@sdau.edu.cn (Z.Z.); cxm_d@tricaas.com (X.C.)
}

Received: 15 April 2019; Accepted: 7 June 2019; Published: 11 June 2019

check for updates

\begin{abstract}
The mirid bugs are one of the most important piercing-sucking insect pests in tea plantations, which severely reduce the quality and economic benefits of tea. In this study, the mirid bug species in the three tea-producing areas in Shandong Province of China were investigated. The distribution and occurrence of dominant species of mirid bugs on four weed host plants and tea plants Camellia sinensis (L.) O. Kuntze (Theaceae) were also studied in the tea agro-ecosystems. The results showed that Apolygus lucorum (Meyer-Dür) (Hemiptera: Miridae) was the dominant mirid bug species in the tea growing areas. Apolygus lucorum densities on Humulus scandens (Lour.) (Moraceae) and Artemisia lavandulaefolia DC. (Asteraceae) were relatively higher than those on Conyza canadensis (Linn) Cronq (Asteraceae), Artemisia annua Linn (Asteraceae), and C. sinensis. Host plant switching of A. lucorum in the tea agro-ecosystem was: A. lucorum scattered on and seriously infested tea plants in June and July; A. lucorum largely migrated to and gathered on $H$. scandens, A. lavandulaefolia, C. canadensis, and $A$. annua at the flowering stage, and population densities of $A$. lucorum on these flowering hosts peaked in late September; in October, A. lucorum gradually moved back to flowering tea plants. These results could provide a reference for selecting host plants, such as Artemisia plants, as trap plants for sustainable control of mirid bugs in tea plantations.
\end{abstract}

Keywords: Apolygus lucorum; tea plants; weed hosts; population change

\section{Introduction}

Mirid bugs (Hemiptera: Miridae) are omnivorous species in natural and agricultural ecosystems throughout the world, and exhibit diverse feeding habits (e.g., feeding on leaf, stem, inflorescences, fruit, and small insects) $[1,2]$. These pestiferous insects can seriously damage a variety of agricultural crops, including cotton, legumes, cereals, vegetables, fruits, and tea plants [3]. In recent years, mirid bugs have become one of the most common and economically important piercing-sucking herbivores of tea plants Camellia sinensis (L.) O. Kuntze (Theaceae). Damage of these insect pests to tea plants has been increasing and harmful in some tea growing regions of northern China [4]. Both adults and nymphs suck the sap from young buds and shoots of tea plants. Small reddish-brown dead spots on the younger tea buds are caused by stylet probing just after infestation of mirid bugs (Figure 1a). The spots of dead tissue gradually form irregular holes in the leaves, or cause the tea leaves to become fragmentary as the buds grow (Figure 1b) [3]. The digestive enzyme polygalacturonase in the salivary glands of mirid bugs plays the most important role in the induction of visible injury on the leaves of 
tea plants [5]. Damage to tea plants caused by feeding of mirid bugs results in a loss of 30-40\% of tender tea shoots during the spring growing season depending on the pest population density, and causes large economic losses and reduction in tea quality [4].
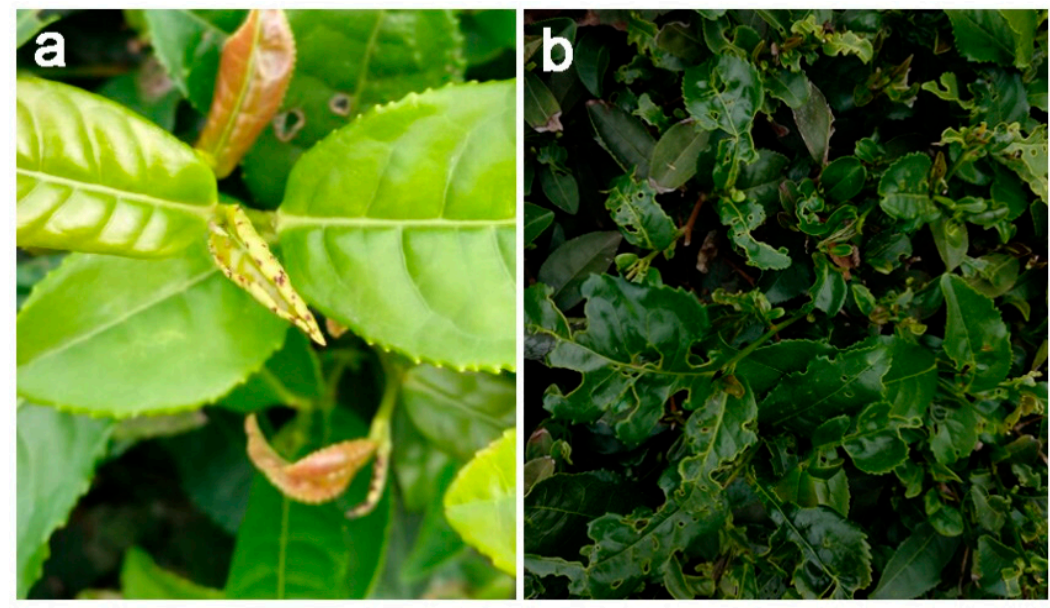

Figure 1. Young tea shoots (a) and tea leaves (b) damaged from probing by mirid bugs.

Mirid bugs have a broad range of host plants, and adults have the capability to undertake long-distance flight among different host plants [6]. For example, 288 plant species in 54 families were found to be the hosts of Apolygus lucorum (Meyer-Dür) (Hemiptera: Miridae) [7,8]. Host switching in A. lucorum might be likely determined by seasonal population density of this insect and host plant availability [9]. In particular, A. lucorum adults switched host plants according to the succession of flowering plant species in the local agro-ecosystem [9]. Humulus scandens (Lour.) (Moraceae), Artemisia lavandulaefolia DC. (Asteraceae), Conyza canadensis (Linn) Cronq (Asteraceae), and Artemisia annua Linn (Asteraceae) are the common weed species which are easy to grow in the agro-ecosystem and have a long blooming period in autumn. Pan et al. [9] found that A. lucorum adults preferred these weed plant species in bloom. However, very little is known about the distribution and host plant switching of mirid bugs in the tea growing areas of northern China, where these insect pests occur seriously.

In the present study, field trials were carried out to investigate the distribution and occurrence of mirid bugs on the tea plants and the four weed plant hosts in the tea agro-ecosystem in Shandong Province of China in 2016 and 2018. Seasonal population change of the dominant mirid bug species was also monitored in 2016. The data can be used to understand the interaction between mirid bugs and host plants and further select specific weed plant hosts as trap plants in area-wide management tactics for mirid bugs in the Chinese tea plantations.

\section{Materials and Methods}

\subsection{Field Experimental Design}

The experiments were conducted in three commercial tea plantations in Tai'an (experiment site 1: $36.221^{\circ} \mathrm{N}, 116.943^{\circ} \mathrm{E}$; experiment site 2: $\left.36.120^{\circ} \mathrm{N}, 117.145^{\circ} \mathrm{E}\right)$, Rizhao $\left(35.207^{\circ} \mathrm{N}, 119.246^{\circ} \mathrm{E}\right)$, and Qingdao $\left(36.266^{\circ} \mathrm{N}, 120.651^{\circ} \mathrm{E}\right)$, Shandong Province, China. H. scandens, A. lavandulaefolia, C. canadensis, and $A$. annua are the common and important weed plant hosts of polyphagous mirid bugs in the agro-ecosystem [1,9]. Four wild weed plant species as potential trap plants were transplanted as seedlings from nearby agricultural fields to the tea plantations. Each weed plant species was established in four separate $4 \times 2$ m plots in early May in both 2016 and 2018, respectively. The seedlings of each weed plant species were planted in nine rows with distances of $25 \mathrm{~cm}$ between the rows and $25 \mathrm{~cm}$ between plants within the rows. The individual plots were positioned at random and spaced at $3 \mathrm{~m}$ intervals. The area planted with potential trap plants was approximately $500 \mathrm{~m}^{2}$, and embedded within the $>10$ ha tea plantations. 


\subsection{Plot Surveys}

The distribution of mirid bugs in three tea-producing areas and the numbers of the dominant mirid bug species on C. sinensis, H. scandens, A. lavandulaefolia, C. canadensis, and A. annua in tea plantation were investigated on 20 September 2016 and on 20 September 2018. The number of mirid bugs in each plot was determined by the knock-down method complemented by visually inspecting plants following Zhang et al. [4] and Pan et al. [9]. Both sampling methods were directed to the upper parts of plants. Knock-down techniques consisted of pulling parts of the tea plants over a rectangular white-colored pan $(60 \times 35 \times 3 \mathrm{~cm})$, after which the plant material was struck five times and the number of dislodged bugs was counted. During the sampling process, the number of mirid bugs was determined by both sampling methods. The mirid bug species, sex and age of individuals were subsequently identified based upon morphological features according to Jiang et al. [3]. Subplots of $1 \times 1 \mathrm{~m}$ were sampled within each plot. To monitor the population change of the dominant mirid bug species A. lucorum on different host plants, sampling was conducted at 10 day intervals in each plot from 5 June to 15 October 2016 in the tea plantations in Daiyue county $\left(36.221^{\circ} \mathrm{N}, 116.943^{\circ} \mathrm{E}\right)$ (experiment site 1$)$ and Taishan county $\left(36.120^{\circ} \mathrm{N}, 117.145^{\circ} \mathrm{E}\right)$ (experiment site 2 ) in Tai'an, Shandong Province, China.

\subsection{Statistical Analysis}

All statistical analyses were performed using SPSS statistical software (version 18.0, SPSS Inc., Chicago, IL, USA). Generalized linear models (GLM) were used in order to know the effects of mirid bug species, tea-producing area and interactions on the numbers of mirid bugs, and the effects of host plant species, tea-producing area and interactions on the number of A. lucorum, respectively. Statistically significant mean values of the numbers of mirid bugs were determined by Tukey's HSD method $(p<0.05)$. GLM followed by Tukey's HSD tests $(p<0.05)$ were also used to compare numbers of females, males, and nymphs of A. lucorum on four different host plants. Significant differences in the A. lucorum population density on the four weed plant hosts and tea plants were determined using repeated-measures analysis of variance (MANOVA), with host plants as the factors and the sample date as the split-plot factor. Multiple comparison in the abundance of A. lucorum among different host plant species was also determined through Tukey's HSD tests $(p<0.05)$.

\section{Results}

\subsection{Dominant Mirid Bug Species in Tea Agro-Ecosystems}

There were significant differences in mirid bug species in the tea agro-ecosystem among the three different tea growing areas (in 2016: $F=45.267, p<0.001$; in 2018: $F=34.225, p<0.001$ ). The interaction between mirid bug species and tea-producing area also significantly affected the numbers of mirid bugs (in 2016: $F=11.735, p<0.001$; in 2018: $F=41.279, p<0.001$ ) (Table 1). Apolygus lucorum was the dominant species in the tea growing areas in Shandong Province of China. In 2016, the population density of A. lucorum in the tea agro-ecosystem in Rizhao was $9.07 \pm 1.70$ per square meter plants, and it was significantly higher than in Qingdao ( $4.93 \pm 0.89$ per square meter plants) and Tai'an $(4.20 \pm 0.10$ per square meter plants) $\left(F_{2,29}=12.412, p<0.001\right)$. In addition, little Adelphocoris fasciaticollis Reuter (1.10 \pm 0.41 per square meter plants) and Adelphocoris sp. ( $0.70 \pm 0.30$ per square meter plants) were found in Tai'an. In 2018, there was no significant difference in the A. lucorum density in all sampling sites (Qingdao: $2.38 \pm 0.46$ per square meter plants; Rizhao: $2.13 \pm 0.52$ per square meter plants; Tai'an: $2.88 \pm 0.58$ per square meter plants) $\left(F_{2,29}=0.537, p=0.592\right)$. For $A$. fasciaticollis, the density of this mirid bug species in Tai'an was significantly higher than in Rizhao in $2018\left(F_{2,29}=3.678, p=0.043\right)$ (Figure 2). 
Table 1. Generalized linear models (GLM) parameters for effects of mirid bug species and tea-producing area on the numbers of mirid bugs.

\begin{tabular}{cccccc}
\hline \multirow{2}{*}{ Source } & \multirow{2}{*}{$\boldsymbol{d f}$} & \multicolumn{2}{c}{$\mathbf{2 0 1 6}$} & \multicolumn{2}{c}{$\mathbf{2 0 1 8}$} \\
\cline { 3 - 6 } & & $\boldsymbol{F}$ & $\boldsymbol{p}$-Values & $\boldsymbol{F}$ & $\boldsymbol{p}$-Values \\
\hline Mirid bug species & 2,63 & 45.267 & $<\mathbf{0 . 0 0 1}$ & 34.225 & $<\mathbf{0 . 0 0 1}$ \\
Tea-producing area & 2,63 & 4.506 & $\mathbf{0 . 0 1 5}$ & 26.430 & 0.051 \\
Mirid bug species $\times$ tea-producing area & 4,63 & 11.735 & $<\mathbf{0 . 0 0 1}$ & 41.279 & $<\mathbf{0 . 0 0 1}$ \\
\hline
\end{tabular}

Bolded $p$-values indicate significant treatment effects $(p<0.05)$.

a

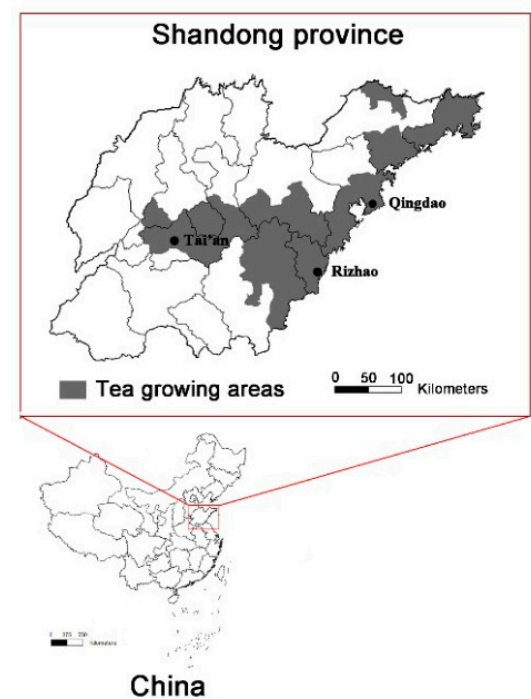

b

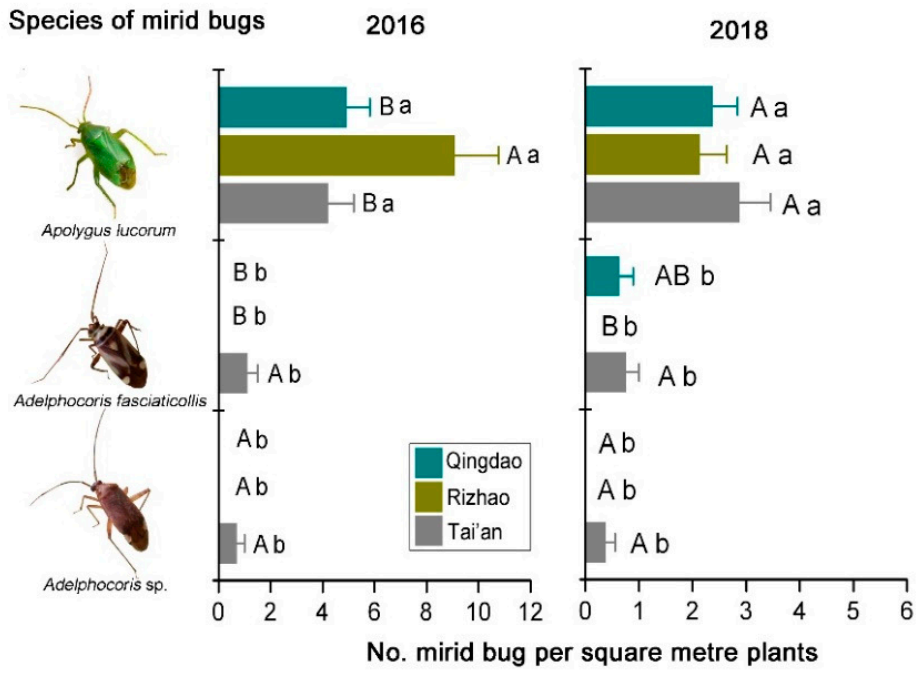

Figure 2. Tea growing areas in Shandong province of China (a) and the distribution of mirid bugs in three tea-producing areas in Shandong Province in 2016 and 2018 (b). Different uppercase and lowercase letters indicate significant differences among different tea-producing areas and different mirid bug species, respectively (Tukey's HSD test, $p<0.05$ ).

\subsection{Distribution of A. lucorum on Main Hosts in Tea Agro-Ecosystems}

There was significant difference in A. lucorum density among different host plant species (in 2016: $F=5.485, p<0.001$; in 2018: $F=4.749, p=0.002$ ). However, the tea-producing area did not significantly affect the numbers of A. lucorum (in 2016: $F=0.035, p<0.965$; in 2018: $F=2.383, p=0.102$ ). The interaction between host plant species and tea-producing area had significant effect on numbers of A. lucorum in 2016 ( $F=6.190, p<0.001)$ (Table 2). In 2016, the A. lucorum densities on C. canadensis (11.50 \pm 1.19 per square meter plants) and $H$. scandens (10.25 \pm 3.30 per square meter plants) were significantly higher than on $C$. sinensis, but not significantly different from $A$. lavandulaefolia and $A$. annua in the tea agro-ecosystem in Tai'an $\left(F_{2,23}=6.654, p=0.003\right)$. In Rizhao, the A. lucorum density on $H$. scandens was 13.75 per square meter plants, and it was significantly higher than on tea plants and other two weed host plants $\left(F_{2,23}=7.906, p=0.001\right)$. In Qingdao, among the different host plants, the highest $A$. lucorum density was found on A. lavandulaefolia $\left(F_{2,23}=7.487, p=0.002\right)$. The A. lucorum density on $C$. canadensis in Tai'an was significantly higher than in Rizhao and Qingdao $\left(F_{2,11}=17.143, p<0.001\right)$. In Qingdao, on A. lavandulaefolia, A. lucorum exhibited higher population density than in Tai' an and Rizhao $\left(F_{2,11}=5.002\right.$, $p=0.035)$. The A. lucorum densities on the tea plants, $H$. scandens, and A. annua were not significantly different among the three different sampling sites, respectively (Figure 3a). In 2018, the A. lucorum density on tea plants in Tai'an was significantly higher than in Rizhao and Qingdao $\left(F_{2,11}=8.806\right.$, $p=0.008)$. Apolygus lucorum populations were not significantly different across host plant species in Tai'an $\left(F_{2,23}=1.057, p=0.411\right)$. The density of $A$. lucorum was significantly higher on $C$. canadensis 
compared with $C$. sinensis in Rizhao $\left(F_{2,23}=3.227, p=0.042\right)$. In Qingdao, more $A$. lucorum were found on A. lavandulaefolia compared with the other host plant species $\left(F_{2,23}=35.713, p<0.001\right)$ (Figure $\left.3 b\right)$.

Table 2. GLM parameters for effects of host plant species and tea-producing area on the number of A. lucorum.

\begin{tabular}{|c|c|c|c|c|c|}
\hline \multirow{2}{*}{ Source } & \multirow{2}{*}{$d f$} & \multicolumn{2}{|c|}{2016} & \multicolumn{2}{|c|}{2018} \\
\hline & & $F$ & $p$-Values & $F$ & $p$-Values \\
\hline Host plant species & 4,45 & 5.485 & 0.001 & 4.749 & 0.002 \\
\hline Tea-producing area & 2,45 & 0.035 & 0.965 & 2.383 & 0.102 \\
\hline Host plant species $\times$ tea-producing area & 8,45 & 6.190 & $<0.001$ & 1.554 & 0.166 \\
\hline
\end{tabular}

Bolded $p$-values indicate significant treatment effects $(p<0.05)$.

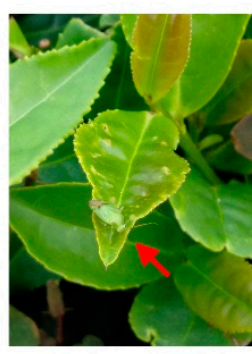

C. sinensis

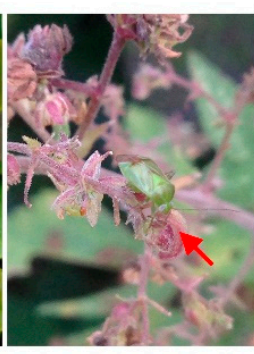

H. scandens

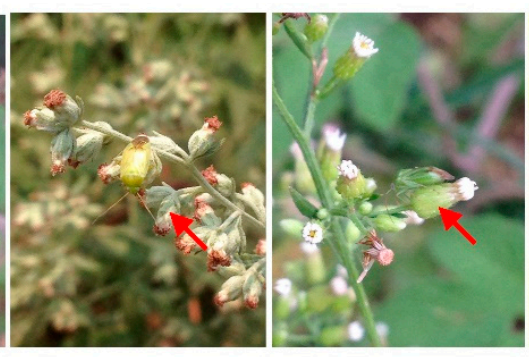

A. lavanduleafolia C. canadensis A. annua

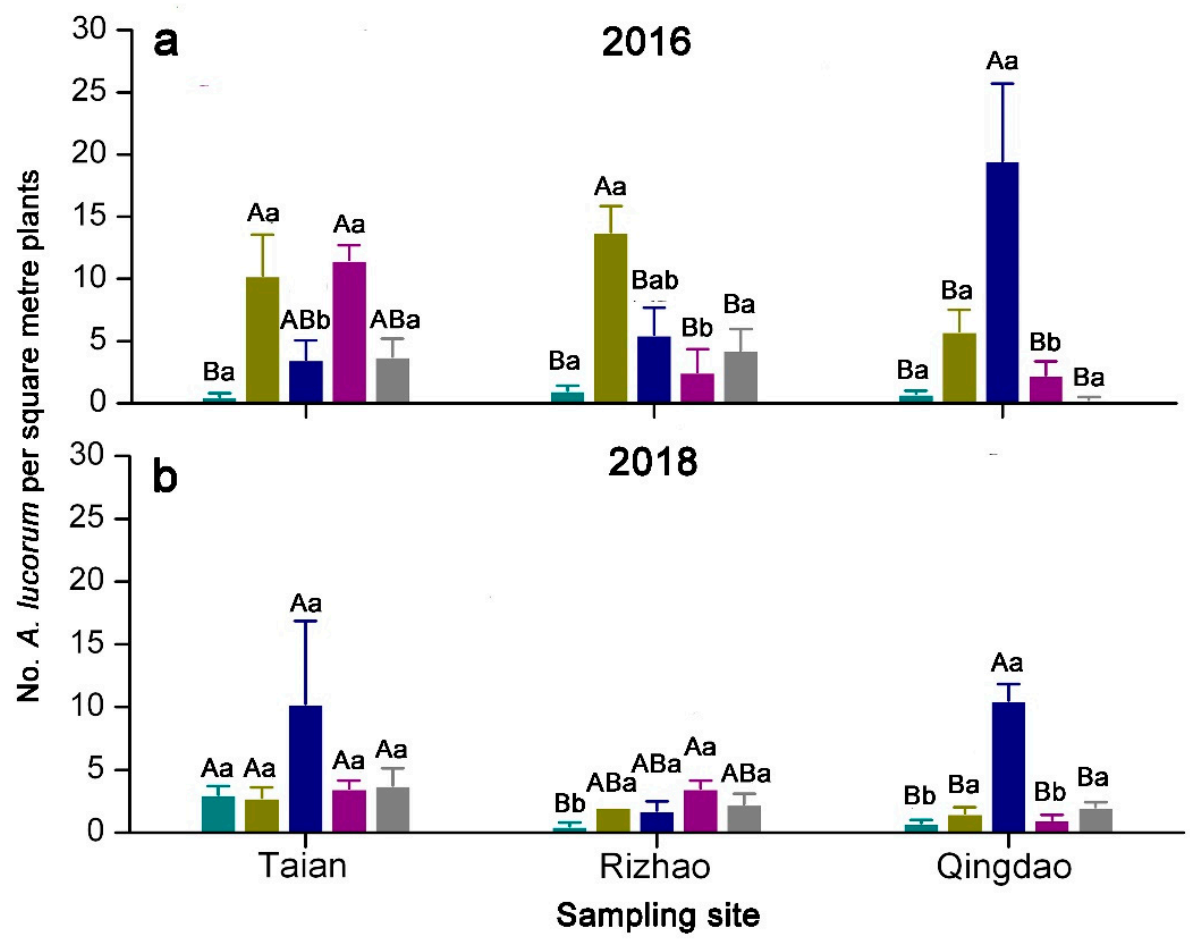

Figure 3. Number of Apolygus lucorum on Camellia sinensis, Humulus scandens, Artemisia lavandulaefolia, Conyza canadensis, and Artemisia annua in tea plantation in different tea-producing areas in 2016 (a) and 2018 (b). Different uppercase and lowercase letters indicate significant differences among different tea-producing areas and different mirid bug species, respectively (Tukey's HSD test, $p<0.05$ ). The red arrows indicate A. lucorum on tea plants and four weed host plants at flowering stage.

In early September, the number of male A. lucorum adults on $H$. scandens was not significantly different compared with female adults, but was significantly higher than nymphs $\left(F_{2,11}=5.318, p=0.022\right)$. There were no significant differences in the number of males, females, and nymphs of A. lucorum on A. lavandulaefolia, C. canadensis, and A. annua, respectively. The number of female $A$. lucorum adults on $H$. scandens was significantly higher than on C. canadensis, but was not significantly different compared 
with A. lavandulaefolia and A. annua $\left(F_{3,19}=4.001, p=0.027\right)$. The number of male $A$. lucorum adults on $H$. scandens was significantly higher than on the other three host plants $\left(F_{3,19}=17.143, p<0.001\right)$. There was no significant difference in the number of $A$. lucorum nymphs among the four host plants $\left(F_{3,19}=2.919, p=0.066\right)$ (Figure 4$)$.

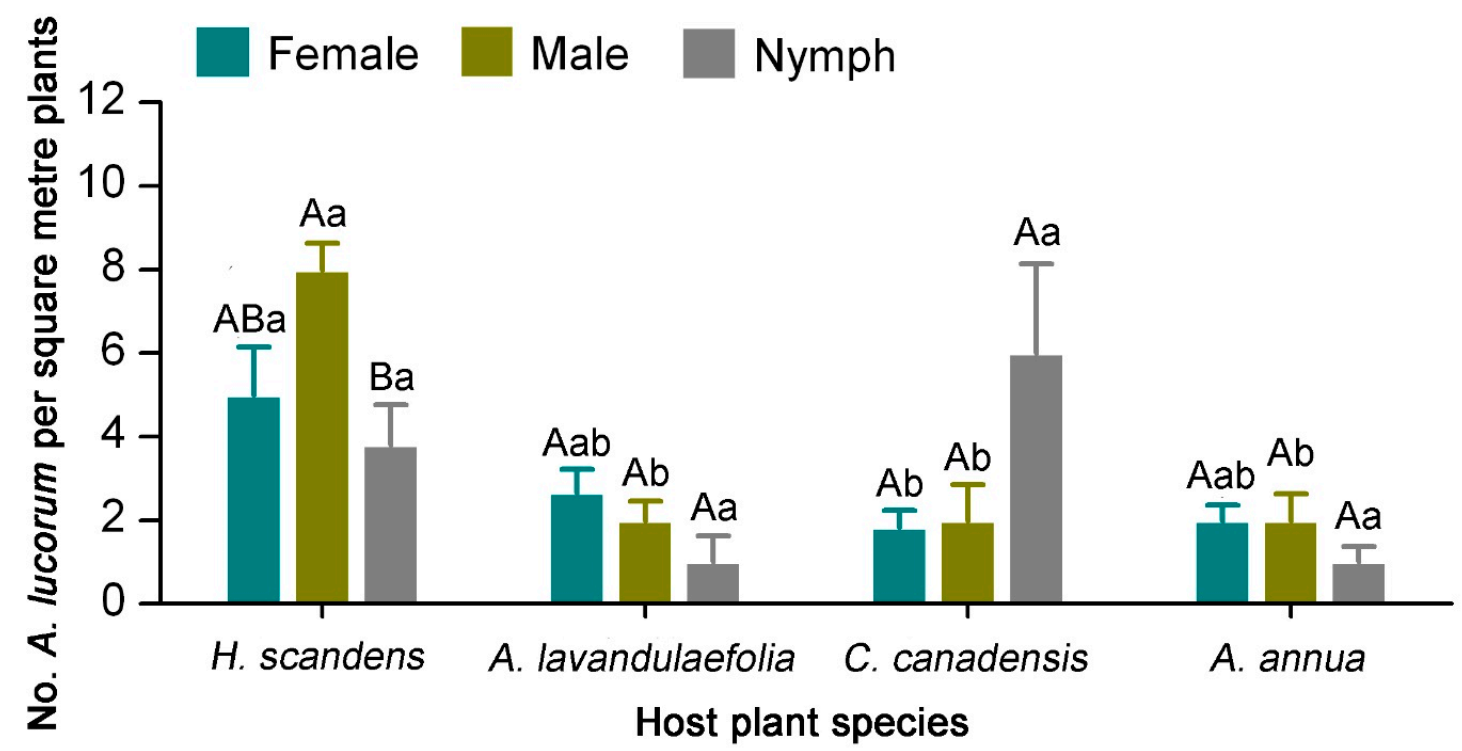

Figure 4. Number of females, males, and nymphs of A. lucorum on four different host plants in tea plantation. Different uppercase letters indicate significant differences among males, females and nymphs and different lowercase letters indicate significant differences among different host plants (Tukey's HSD test, $p<0.05$ ).

\subsection{Population Change of A. lucorum on Tea Plants and Weed Hosts}

In experimental site $1, A$. lucorum infested tea plants in the tea agro-ecosystem in June and July. The highest population density of A. lucorum occurred on the tea plants on 15 June 2016, reaching 1.25 \pm 0.25 per square meter plants. In mid-August, the host plants of $A$. lucorum such as $H$. scandens, $A$. lavandulaefolia, C. canadensis, and A. annua began to flower and bloom. Apolygus lucorum largely migrated to these flowering plants and gathered on them. On 5 September, A. lucorum density on A. lavandulaefolia reached its maximum value of $6.00 \pm 1.35$ per square meter plants. Apolygus lucorum reached peak abundance on $H$. scandens, C. canadensis, and A. annua on 25 September (H. scandens: $10.25 \pm 3.30$ per square meter plants; $C$. canadensis: $11.50 \pm 1.19$ per square meter plants; $A$. annua: $3.75 \pm 1.44$ per square meter plants). In October, the number of A. lucorum on H. scandens, A. lavandulaefolia, C. canadensis, and $A$. annua declined gradually, and these insects were found on the tea plants again (Figure 5a). In experimental site 2, A. lucorum was also found on tea plants in June and July. The highest population density of A. lucorum on $H$. scandens occurred in mid-September, and was significantly higher than the densities on tea plants and other three weed hosts $\left(F_{4,19}=23.235, p<0.001\right)$. The population density of A. lucorum on A. lavandulaefolia peaked on 25 September. However, this value was significantly higher than $C$. canadensis, A. annua, and tea plants, but not significantly different compared with $H$. scandens $\left(F_{4,19}=9.972, p<0.001\right)$. In October, $A$. lucorum migrated into the tea plantations (Figure 5c). Overall, seasonal density of $A$. lucorum on tea plants was not significantly different compared with densities on four weed hosts as potential trap plants in two of the experimental sites (Figure 5b,d). 


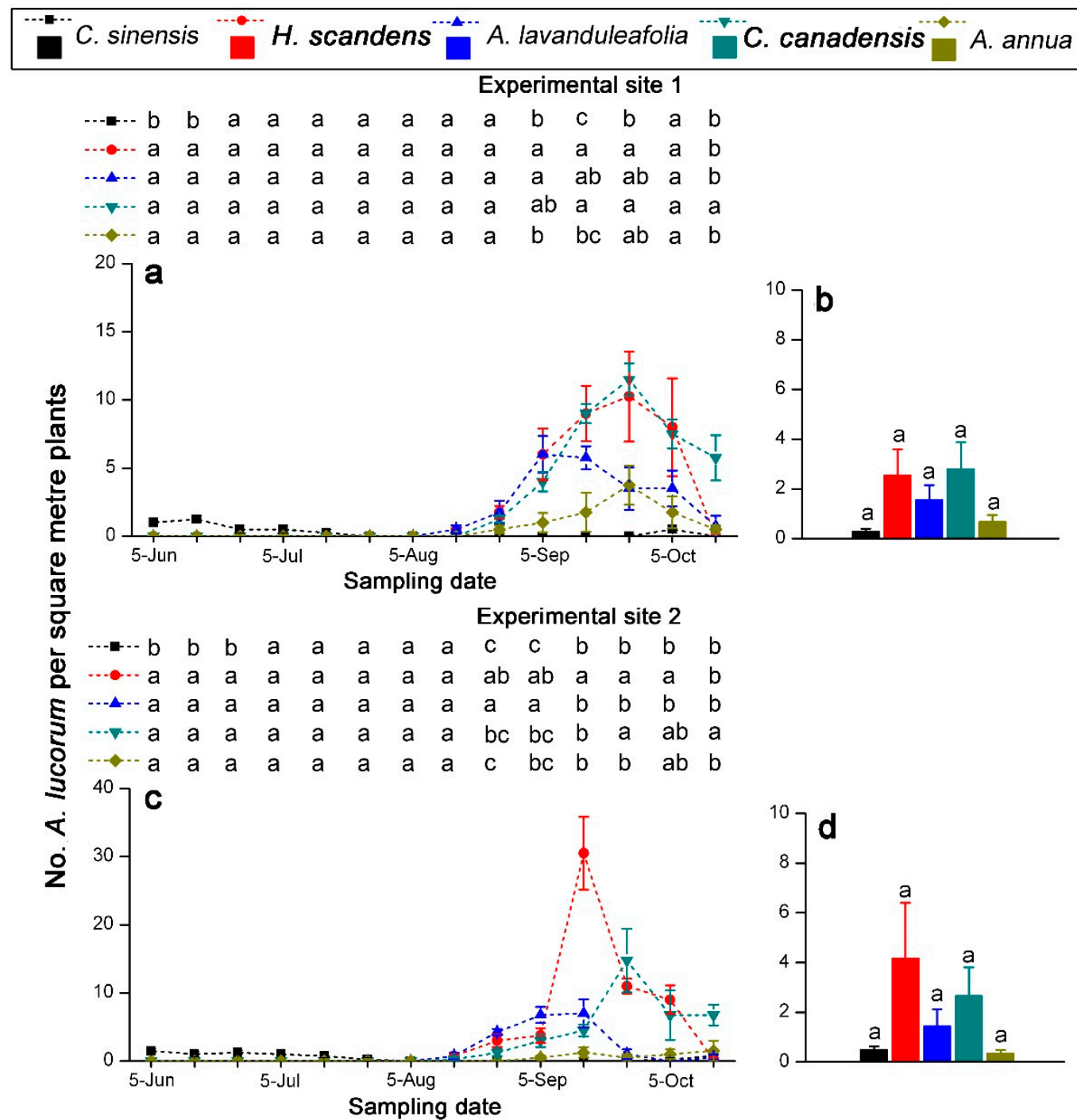

Figure 5. Seasonal changes of population density $(\mathbf{a}, \mathbf{c})$ and seasonal density $(\mathbf{b}, \mathbf{d})$ of A. lucorum on tea plants and four weed host plants in the tea agro-ecosystem in 2016. Different letters indicate significant differences among different host plants (Tukey's HSD test, $p<0.05$ ).

The host plants and sampling date significantly affected the number of A. lucorum on the host plants in the tea agro-ecosystem $(p<0.001)$. Furthermore, the interaction between host plants and sampling date also had a significant effect on population change of A. lucorum $(p<0.001)$ (Table 3$)$.

Table 3. Repeated measures MANOVA parameters for effects of host plants, sampling date, and interactions on population dynamics of A. lucorum on host plants.

\begin{tabular}{cccccc}
\hline & & \multicolumn{2}{c}{$\begin{array}{c}\text { Experimental } \\
\text { Site 1 }\end{array}$} & \multicolumn{3}{c}{$\begin{array}{c}\text { Experimental } \\
\text { Site 2 }\end{array}$} \\
\cline { 3 - 6 } & $d f$ & $\boldsymbol{F}$ & $p$-Values & $\boldsymbol{F}$ & $p$-Values \\
\hline Host plant & 4,210 & 22.661 & $<\mathbf{0 . 0 0 1}$ & 29.259 & $<\mathbf{0 . 0 0 1}$ \\
Sampling date & 13,210 & 29.679 & $<\mathbf{0 . 0 0 1}$ & 26.430 & $<\mathbf{0 . 0 0 1}$ \\
Host plant $\times$ sampling date & 52,210 & 5.123 & $<\mathbf{0 . 0 0 1}$ & 12.836 & $<\mathbf{0 . 0 0 1}$ \\
\hline
\end{tabular}




\section{Discussion}

Apolygus lucorum was the dominant mirid bug species on C. sinensis in the tea growing areas in Shandong Province of China. Meanwhile, a small amount of Adelphocoris spp. occurred in some tea gardens (Figure 2). Apolygus lucorum and Adelphocoris spp. can infest a wide variety of crops including cotton, Chinese dates, apples, pears, grapes, and tea plants in northern China, and the mirid bugs cause serious yield losses [10,11]. For example, A. lucorum and Adelphocoris spp. have emerged as economically important insect pests of cotton for thirty years and cause serious yield losses in the Yangtze River and the Yellow River cotton growing regions of China [12-14]. It is noteworthy that A. lucorum is the dominant mirid bug species in Chinese agro-landscapes and has become the primary pest of several key agricultural crops over the past decade [11].

In the tea plantations, A. lucorum adults laid eggs inside some tea plant tissues, such as the pith of dead branches with pruning wounds and the floral receptacle [15]. In April, the overwintering eggs of A. lucorum begin to hatch and the newly emerged nymphs feed on tender buds of tea plants. During the initial period of infestation, the highly mobile mirid bug nymphs can induce significant cryptic damage which is difficult to be detected [16]. Therefore, mirid bugs, mainly A. lucorum, can seriously damage tea plants in early spring, and cause estimated tea yield losses ranging from $30 \%$ to $40 \%$ of the total tea tender shoots [4]. Apolygus lucorum adults also prefer to deposit eggs for overwintering in the dead parts of branches of fruit trees such as the Chinese date Ziziphus jujuba Mill. and the grape Vitis vinifera $\mathrm{L}$. where the eggs are less likely to be affected by plant growth, which makes weather conditions the most important factor evoking egg hatching $[7,16]$. Overwintering eggs of A. lucorum begin to hatch in April, and the newly emerged nymphs feed on the tender leaves, buds and flowers and cause serious damage. Weather conditions, especially rainfall, were the most important factor evoking overwintering eggs of $A$. lucorum hatching in the dead parts of tree hosts [3,16]. Therefore, during the spring season, rainfall can strongly affect the population densities of A. lucorum in agroecological systems which determine the degree of plant damage.

The polyphagous species $A$. lucorum prefers to feed on the relatively energy-rich plant tissues in flowers and buds. To locate suitable food, A. lucorum adults showed a clear preference for flowering host plants and switched food plants according to the succession of different flowering plant species [1,9]. In late August, A. lucorum gathered on $H$. scandens and Artemisia plants at flowering stage in the tea agro-ecosystem (Figure 5). The high preferences of $A$. lucorum on flowering plants indicated that flowers and flower nectars might be an optimal food for this pest, and some nutrients from flowers might be the most important for its survival, development, and fecundity [17]. This strategy of host plant switching also can avoid intra- and interspecific competition of mirid bugs for host plants [9]. The preferences of $A$. lucorum on flowering hosts were not just for feeding, but also for female oviposition [18]. Moreover, A. lucorum adults and nymphs usually have similar feeding habits, with both life stages consuming plant tissues, nectar, and pollen $[17,19]$. Both adults and nymphs simultaneously existed on the flowering hosts indicated that some eggs of A. lucorum were laid and hatched and the fifth generation was completed on these host plants (Figure 4). In October, population density of A. lucorum on $H$. scandens, A. lavandulaefolia, C. canadensis and A. annua declined gradually at the end of the bloom period, and this pest was detected on the tea plants which are at full-bloom stage (Figure 5). Dong et al. [17] found that female A. lucorum preferred to lay significantly more eggs on flowering host plants. After supplementing with nutrients on the flowering weed hosts, A. lucorum adults of the fifth generation moved back into tea gardens to lay eggs in the dead parts of tea plants for overwintering. Apolygus lucorum density in the tea plantations might be positively associated with the abundance of flowering of tea plants. Further investigation would be required to demonstrate the movement of A. lucorum adults from weed hosts to tea fields at the landscape level exploiting the plant DNA detection approach $[18,20]$. In conclusion, our elucidation of occurrence and distribution of A. lucorum on weed hosts and tea plants will contribute to the development of sustainable management strategies, such as "push-pull" strategy, for A. lucorum in the tea plantation ecosystem. 
The "push-pull" habitat management strategy, as a new powerful and effective tool in integrated pest management, uses a combination of behavior-modifying stimuli to manipulate the distribution and abundance of pests and/or their natural enemies for pest control [21]. In this system, highly attractant trap plants release behavior-manipulating semiochemicals that attract the targeted pests to expected areas in which they are subsequently concentrated. One of the most well-known systems is the "push-pull" strategy for the control of cereal stemborers in maize-based farming system in eastern Africa [21]. Napier grass Pennisetum purpureum and Sudan grass Sorghum sudanense releasing six active compounds effectively attract stemborer moths from maize crop [22,23]. Previous study showed that Vigna radiatus had been identified as a potential trap crop for A. lucorum in Bt cotton fields [24]. During the autumn season, A. lucorum largely aggregated on flowering weed hosts which were chosen as potential trap plants in the tea agro-ecosystem. The A. lucorum densities on H. scandens and A. lavandulaefolia were significantly higher than on tea plants when these weed hosts were at the flowering stage in September and October (Figures 3 and 5). Active compounds such as butyl acrylate, butyl propionate, and butyl butyrate released by $\mathrm{H}$. scandens and Artemisia plants at the flowering stage mediated A. lucorum's preference to flowering host plants [25]. Hence, the flowering host plants planted in tea plantations can be used as trap plants to attract and aggregate A. lucorum due to host plant-mired bug interactions and their emission of behavior-manipulating semiochemicals. Then, some chemical or physical measures could be used to eliminate A. lucorum gathering on these plants to avoid these pests migrating on tea plants again. Because H. scandens and C. canadensis are the vicious weed species in tea gardens, the prospect of using these plants as trap plants for manage A. lucorum is negligible. Artemisia plants are nontoxic and safe to organisms and the environment and can also be used in traditional Chinese medicine. So, Artemisia plants, especially A. lavandulaefolia, are suitable for being applied as trap plants for sustainable control of A. lucorum in tea plantations by means of supplying "push" stimuli.

\section{Conclusions}

Apolygus lucorum was the dominant mirid bug species in the tea plantation ecosystem, and a small amount of Adelphocoris spp. also occurred. Apolygus lucorum can infest a wide variety of crops including tea plants and caused serious yield losses of tender tea shoots during the spring growing season. In June and July, A. lucorum dispersed into tea plantations and seriously infested tea plants. Apolygus lucorum migrated from tea plants to and gathered on $\mathrm{H}$. scandens and Artemisia plants at flowering stage in late August, and got nutrients from flowers for its survival, development, and fecundity. Apolygus lucorum reappeared on the flowering tea plants from the beginning of October and lay eggs in the dead parts of tea plants for overwintering. Apolygus lucorum densities on H. scandens and A. lavandulaefolia were relatively higher than those on C. canadensis, A. annua, and tea plants. Hence, the flowering Artemisia plants especially A. lavandulaefolia could be used as trap plants to attract and aggregate A. lucorum, and be more efficient to manage this tea pest in large-scale tea plantations. The use of Artemisia plants may also reduce the use of pesticides in tea crops and may contribute to a reduction of costs for the local tea farmers in the long run. In the future, this ecology control tactic may be incorporated as part of an integrated pest management (IPM) strategy for the control of A. lucorum and may be widely adopted by Chinese tea farmers.

Author Contributions: Conceptualization, Y.T., Z.Z. and X.C.; methodology, Y.T. and H.W.; software, Y.T. and Z.Z.; validation, Y.T., Z.Z. and X.C.; formal analysis, Y.T. and Z.Z.; investigation, Y.T., H.W., J.H. and Z.Z.; resources, J.H. and L.Z.; data Curation, Y.T.; writing—original draft preparation, Y.T. and Z.Z.; writing—review and editing, Z.Z. and X.C.; visualization, Z.Z. and X.C.; supervision, Z.Z. and X.C.; project administration, Z.Z. and X.C.; funding acquisition, Z.Z. and X.C.

Funding: This work was financially supported by a grant from the National Key Research and Development Program of China (2016YFD0200900), the National Natural Science Foundation of China (31501651), Major Project for Agricultural Application Technology Innovation of Shandong Province (20182130106), Modern Tea Industry Technology System of Shandong Province (SDAIT-19-04), and Funds of Shandong “Double Tops" Program. 
Acknowledgments: The authors are grateful to the funder. We are grateful to other field entomologists and technicians in Tai'an, Qingdao, and Rizhao in Shandong Province in China for technical and other assistance.

Conflicts of Interest: The authors declare no conflict of interest.

\section{References}

1. Pan, H.; Liu, B.; Lu, Y.; Wyckhuys, K.A.G. Seasonal alterations in host range and fidelity in the polyphagous mirid bug, Apolygus lucorum (Heteroptera: Miridae). PLoS ONE 2015, 10, e0117153. [CrossRef] [PubMed]

2. Li, W.; Zhao, X.; Yuan, W.; Wu, K. Activities of digestive enzymes in the omnivorous pest Apolygus lucorum (Hemiptera: Miridae). J. Econ. Entomol. 2017, 110, 101-110. [PubMed]

3. Jiang, Y.Y.; Lu, Y.H.; Zeng, J. Forecast and Management of Mirid Bugs in Multiple Agroecosystems of China; China Agriculture Press: Beijing, China, 2015; pp. 16-18.

4. Zhang, Z.; Zhou, C.; Xu, Y.; Huang, X.; Zhang, L.; Mu, W. Effects of intercropping tea with aromatic plants on population dynamics of arthropods in Chinese tea plantations. J. Pest Sci. 2017, 90, 227-237. [CrossRef]

5. Zhang, L.; Lu, Y.; Liang, G. A method for field assessment of plant injury elicited by the salivary proteins of Apolygus lucorum. Entomol. Exp. Appl. 2013, 149, 292-297. [CrossRef]

6. Lu, Y.; Wu, K.; Guo, Y. Flight potential of Lygus lucorum (Meyer-Dür) (Heteroptera: Miridae). Environ. Entomol. 2007, 36, 1007-1013. [PubMed]

7. Lu, Y.H.; Wu, K.M.; Wyckhuys, K.A.G.; Guo, Y.Y. Overwintering hosts of Apolygus lucorum (Hemiptera: Miridae) in northern China. Crop Prot. 2010, 29, 1026-1033. [CrossRef]

8. Lu, Y.H.; Jiao, Z.B.; Wu, K.M. Early season host plants of Apolygus lucorum (Heteroptera: Miridae) in northern China. J. Econ. Entomol. 2012, 105, 1603-1611. [CrossRef]

9. Pan, H.; Lu, Y.; Wyckhuys, K.A.G.; Wu, K. Preference of a polyphagous mirid bug, Apolygus lucorum (Meyer-Dür) for flowering host plants. PLoS ONE 2013, 8, e68980. [CrossRef] [PubMed]

10. Lu, Y.H.; Qiu, F.; Feng, H.Q.; Li, H.B.; Yang, Z.C.; Wyckhuys, K.A.G.; Wu, K.M. Species composition and seasonal abundance of pestiferous plant bugs (Hemiptera: Miridae) on Bt cotton in China. Crop Prot. 2008, 27, 465-472. [CrossRef]

11. Lu, Y.H.; Wu, K.M.; Jiang, Y.Y.; Xia, B.; Li, P.; Feng, H.Q.; Wyckhuys, K.A.G.; Guo, Y.Y. Mirid bug outbreaks in multiple crops correlated with wide-scale adoption of Bt cotton in China. Science 2010, 328, 1151-1154. [CrossRef]

12. Lu, Y.H.; Wu, K.M. Mirid bugs in China: Pest status and management strategies. Outlooks Pest Manag. 2011, 22, 248-252. [CrossRef]

13. Wu, K.M.; Lu, Y.H.; Feng, H.Q.; Jiang, Y.Y.; Zhao, J.Z. Suppression of cotton bollworm in multiple crops in China in areas with Bt toxin-containing cotton. Science 2008, 321, 1676-1678. [CrossRef] [PubMed]

14. Zhang, W.; Lu, Y.; van der Werf, W.; Huang, J.; Wu, F.; Zhou, K.; Deng, X.; Jiang, Y.; Wu, K.; Rosegrant, M.W. Multidecadal, county-level analysis of the effects of land use, Bt cotton, and weather on cotton pests in China. Proc. Natl. Acad. Sci. USA 2018, 115, 7700-7709. [CrossRef]

15. Duan, Y.; Zheng, H.; Dong, S.; Song, D. Study on the annual population dynamics of Apolygus lucorum in the tea plantation in northern China. J. Shandong Agric. Univ. 2017, 48, $24-27$.

16. Pan, H.; Liu, B.; Lu, Y.; Desneux, N. Identification of the key weather factors affecting overwintering success of Apolygus lucorum eggs in dead host tree branches. PLoS ONE 2014, 9, e94190. [CrossRef] [PubMed]

17. Dong, J.W.; Pang, H.S.; Lu, Y.H.; Yang, Y.Z. Nymphal performance correlated with adult preference for flowering host plants in a polyphagous mirid bug, Apolygus lucorum (Heteroptera: Miridae). Arthropod-Plant Interact. 2013, 7, 83-91. [CrossRef]

18. Wang, Q.; Bao, W.; Yang, F.; Yang, Y.; Lu, Y. A PCR-based analysis of plant DNA reveals the feeding preferences of Apolygus lucorum (Heteroptera: Miridae). Arthropod-Plant Interact. 2018, 12, 567-574. [CrossRef]

19. Wäckers, F.L.; Romeis, J.; van Rijn, P. Nectar and pollen feeding by insect herbivores and implications for multitrophic interactions. Annu. Rev. Entomol. 2007, 52, 301-323. [CrossRef]

20. Wang, Q.; Bao, W.F.; Yang, F.; Xu, B.; Yang, Y.Z. The specific host plant DNA detection suggests a potential migration of Apolygus lucorum from cotton to mungbean fields. PLoS ONE 2017, 12, e0177789. [CrossRef]

21. Cook, S.M.; Khan, Z.R.; Pickett, J.A. The use of push-pull strategies in integrated pest management. Ann. Rev. Entomol. 2007, 52, 375-400. [CrossRef] 
22. Khan, Z.R.; Ampong-Nyarko, K.; Chiliswa, P.; Hassanali, A.; Kimani, S.; Lwande, W.; Overholt, W.A.; Picketta, J.A.; Smart, L.E.; Woodcock, C.M. Intercropping increases parasitism of pests. Nature 1997, 388, 631-632. [CrossRef]

23. Khan, Z.R.; Pickett, J.A.; van den Berg, J.; Wadhams, L.J.; Woodcock, C.M. Exploiting chemical ecology and species diversity: Stem borer and striga control for maize and sorghum in Africa. Pest Manag. Sci. 2000, 56, 957-962. [CrossRef]

24. Lu, Y.H.; Wu, K.M.; Wyckhuys, K.A.G.; Guo, Y.Y. Potential of mungbean, Vigna radiatus as a trap crop for managing Apolygus lucorum (Hemiptera: Miridae) on Bt cotton. Crop Prot. 2009, 28, 77-81. [CrossRef]

25. Pan, H.; Lu, Y.; Xiu, C.; Geng, H.; Cai, X.; Sun, X.; Zhang, Y.; Williams, L., III; Wyckhuys, K.A.G.; Wu, K. Volatile fragrances associated with flowers mediate host plant alternation of a polyphagous mirid bug. Sci. Rep. 2015, 5, 14805. [CrossRef] [PubMed]

(C) 2019 by the authors. Licensee MDPI, Basel, Switzerland. This article is an open access article distributed under the terms and conditions of the Creative Commons Attribution (CC BY) license (http://creativecommons.org/licenses/by/4.0/). 